\title{
APPLICATION OF LEXICOGRAPHIC METHODS IN FINDING NEW SOLUTIONS FOR THE CONSTRUCTION OF SWITCH FAUCETS
}

\author{
VLAD ANDREI CIUBOTARIU1 ${ }^{1}$, IONEL OLARU ${ }^{*}$, CRINA MARIA RADU ${ }^{1}$, \\ COSMIN GRIGORAS ${ }^{1}$
}

1 "Vasile Alecsandri" University of Bacau, Calea Marasesti 157, Bacau, 600115, Romania

\begin{abstract}
Methods and techniques to stimulate creativity are indispensable in the process of obtaining more reliable and competitive products. For the elaboration and efficient use of logical-deductive methods and techniques in creativity, it is necessary to know a minimum of combinatorics, which include arrangements, combinations, permutations, graphs and finite networks. From the multitude of methods of orderly enumeration of all ensembles, without omissions or repetitions, the lexicographic method is recommended, according to which, the assemblies are ordered in ascending order according to the sum of the component elements index. The main purpose of this paper is to apply the lexicographic method to obtain a more efficient flow faucet body in terms of working fluid behavior. Thus, the pressure, flow, velocity variation and degree of fluid vorticity have better values for the faucet body obtained by applying the lexicographic method. Therefore, by applying the flow simulation method, it was possible to characterize the behavior of the working fluid.
\end{abstract}

Keywords: technical creativity, creativity stimulation, flow valve, flow simulation

\section{INTRODUCTION}

The increase in the volume of knowledge and human creations has also been illustrated by some statistics. Thus, it is estimated that the number of distinct products made by humans is in the order of tens of millions. It turned out that $99.5 \%$ of these products were created and made in the last two centuries and $0.5 \%$ of them were made in the entire history of almost 10 millennia of human creation [1]. The increase of the level of knowledge and human creations led to the development of the society, further determining the increase of the number of created products. The knowledge or information gained made man develop and the process once initiated could not be stopped. Thus, it can be stated that: information means development and development forces the new [2].

The product of creation is the best known and most obvious criterion for creativity assessment. The product of creation is expressed either in something material such as: an object, a project, an object of art, or in something immaterial (intellectual or cultural) such as: a theory, a principle, a formula, an interpretation [3].

The knowledge fund is the starting point and continuous supply for the synthesis of new solutions. The background of methods and strategies for stimulating creativity is structured on analytical (most used in engineering) and imaginative methods [4]. Analytical methods are based on the predominant use of logical thinking, without excluding intuitive thinking, in order to stimulate the process of combining in real terms with the use of information directly related to the problem to be solved.

\footnotetext{
* Corresponding author, e-mail: ionelo@ub.ro

(c) 2020 Alma Mater Publishing House
} 
These methods involve dividing the problem into all its components, analyzing it from all possible angles, listing all the criteria, and then to consider, in turn, each possibility. It is based on lists or matrices that ensure a certain ordering of the work data before being analyzed. Lists or matrices are more of a tool that directs the creative effort and helps to cover as many aspects as possible [4].

For the design and efficient use of analytical (logical-deductive) methods in the field of technical creativity, it is necessary to know a minimum of notions of combinatorics, which include arrangements, combinations, permutations, graphs and finite networks. Although analytical methods are individually applied techniques, they can also be worked on within the group, the success of the application depending to a certain extent on the volume and diversity of the information available.

With all this in mind, many of the products already invented a long time ago cannot be changed much other than somehow to increase operational efficiency. Thus, one of the categories subject to attention is domestic and industrial water / gas faucets or taps.

Water and gas faucets have adjustable flow: globe faucets are frequently used in on/off applications, but gate faucets are more progressive. By changing the opening of the control device in the faucet's assembly, the flow is adjusted. The flow rate is independent of the temperature or viscosity of the fluid and depends slightly on the pressure, so that the flow is unchanging at a certain setting. At very low flow settings, the viscosity of the water becomes important, and the pressure drop disappears. In the case of intermediate flow settings, cold water vapor bubbles form and collapse under restriction, causing a whistle noise due to Venturi effect. At the working flow settings, the drag force in the pipes become important and the water becomes silent again [5].

Taking into account all this information, by applying the various techniques and methods proposed in the field of technical creativity, new constructive models of these faucets can be obtained.

\section{METHODOLOGY FOR APPLYING THE LEXICOGRAPHIC TECHNIQUE}

\subsection{Lexicographic technique}

In order to apply this technique, the component to be analyzed must first be described. Thus, in this paper it is proposed to improve a faucet body of the type shown in Figure 1. The part in question is a "globe valve" body type and has two coaxial ports, because it is designed for the case where the input pipe is aligned with the output pipe and the fluid can pass without too many problems.

The two halves of the faucet body are separated by a baffle which, in addition to its basic function as a restriction, creates turbulence and vortices in the working fluid by the mere presence. This baffle has a bore that generates a seat through which a movable plug is inserted, starting or stopping the flow of fluid. Generally, the plug is connected to a rod which is moved by either a screw or an actuator. In turn, the screw or actuator is connected to the faucet body by means of a threaded bonnet.
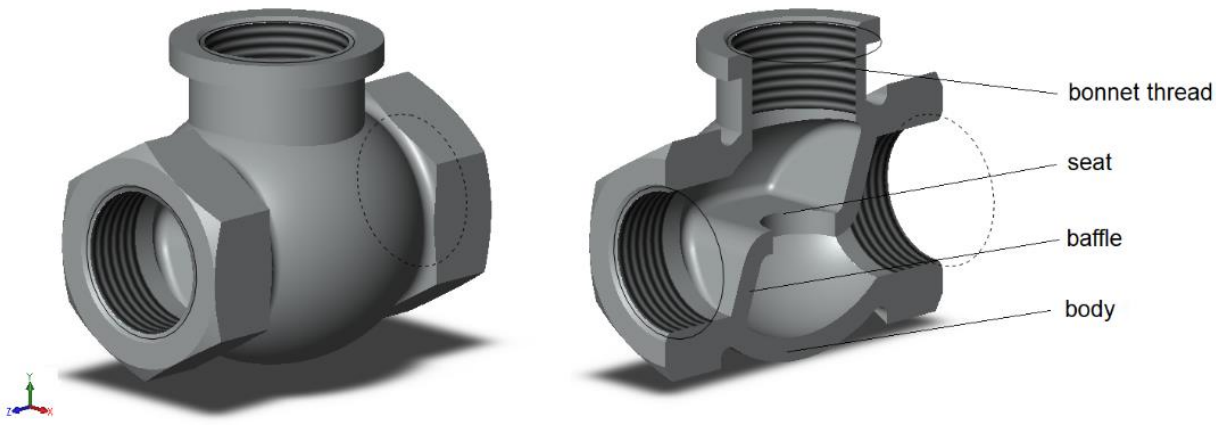

Fig. 1. Faucet body of a ,globe valve” type.

From the multitude of methods found in technical creativity regarding orderly enumeration of all assemblies (less than 100), without omissions or repetitions, the lexicographic method is recommended [4], according to which, the assemblies are arranged in ascending order according to the sum of the indices of the component elements. 
Knowing all this, for the application of the lexicographic technique, the faucet must be analyzed from several points of view, which will create a morphological ensemble.

Thus, four components of the morphological assembly created for the faucet are presented in Table 1 . Therefore, the following formative ensembles are considered: $A=\left[a_{1}, a_{2}, a_{3}\right], B=\left[b_{1}, b_{2}, b_{3}, b_{4}, b_{5}\right], C=\left[c_{1}, c_{2}\right], D=\left[d_{1}, d_{2}\right.$, $\left.\mathrm{d}_{3}\right]$.

Assemblies are formed in ascending order, with a minimum amount of 4 (corresponding to the minimum values of the four elements - 1), up to a maximum of 13 (corresponding to the maximum values of the four elements - 3 , 5, 2 and 3). The order of the assemblies can be represented tabularly or graphically, where the $3 \times 5 \times 2 \times 3=90$ possible solutions can be transposed into a vector network. Therefore, due to lack of space in this paper, most of the combinations of all four formative ensembles are shown in the constructive combination matrix (Table 2).

Table 1. Morphological ensemble regarding the analysis of the globe valve type of faucet.

\begin{tabular}{|c|c|c|}
\hline Symbol & Components & Constructive solutions \\
\hline A & Drive components & $\begin{array}{l}\text { 1. screw } \\
\text { 2. bow (button) } \\
\text { 3. lever (butterfly) }\end{array}$ \\
\hline $\mathrm{B}$ & Fluid blocking components & $\begin{array}{l}\text { 1. disc (butterfly) } \\
\text { 2. plug } \\
\text { 3. ball (cone) } \\
\text { 4. gate } \\
\text { 5. flap (cover) }\end{array}$ \\
\hline $\mathrm{C}$ & Passage space & $\begin{array}{l}\text { 1. free space } \\
\text { 2. grid }\end{array}$ \\
\hline $\mathrm{D}$ & $\begin{array}{l}\text { Position of the rod or its } \\
\text { movement relative to the axis of } \\
\text { the faucet body }\end{array}$ & $\begin{array}{l}\text { 1. vertical (radial) } \\
\text { 2. horizontal (axial) } \\
\text { 3. tilted }\end{array}$ \\
\hline
\end{tabular}

Table 2. Constructive combination matrix.

\begin{tabular}{|c|c|c|c|c|c|c|c|c|c|c|c|}
\hline Group & Index & \multicolumn{10}{|c|}{ Combinations } \\
\hline 1 & 4 & $\mathrm{a}_{1} \mathrm{~b}_{1} \mathrm{c}_{1} \mathrm{~d}_{1}$ & & & & & & & & & \\
\hline 2 & 5 & $a_{1} b_{1} c_{1} d_{2}$ & $\mathrm{a}_{1} \mathrm{~b}_{1} \mathrm{c}_{2} \mathrm{~d}_{1}$ & $\mathrm{a}_{1} \mathrm{~b}_{2} \mathrm{c}_{1} \mathrm{~d}_{1}$ & $\mathrm{a}_{2} \mathrm{~b}_{1} \mathrm{c}_{1} \mathrm{~d}_{1}$ & & & & & & \\
\hline 3 & 6 & $a_{1} b_{1} c_{1} d_{3}$ & $a_{1} b_{1} c_{2} d_{2}$ & $\mathrm{a}_{1} \mathrm{~b}_{2} \mathrm{c}_{1} \mathrm{~d}_{2}$ & $a_{2} b_{1} c_{1} d_{2}$ & $\ldots$ & $a_{3} b_{1} c_{1} d_{1}$ & $a_{1} b_{3} c_{1} d_{1}$ & & & \\
\hline 4 & 7 & $\mathrm{a}_{1} \mathrm{~b}_{4} \mathrm{c}_{1} \mathrm{~d}_{1}$ & $\mathrm{a}_{2} \mathrm{~b}_{3} \mathrm{c}_{1} \mathrm{~d}_{1}$ & $\mathrm{a}_{2} \mathrm{~b}_{2} \mathrm{c}_{2} \mathrm{~d}_{1}$ & $\mathrm{a}_{2} \mathrm{~b}_{2} \mathrm{c}_{1} \mathrm{~d}_{2}$ & $\ldots$ & $a_{1} b_{2} c_{1} d_{3}$ & $a_{1} b_{2} c_{2} d_{2}$ & $\ldots$ & $\mathrm{a}_{2} \mathrm{~b}_{1} \mathrm{c}_{2} \mathrm{~d}_{2}$ & \\
\hline 5 & 8 & $a_{2} b_{2} c_{2} d_{2}$ & $a_{1} b_{3} c_{1} d_{3}$ & $a_{1} b_{2} c_{2} d_{3}$ & $a_{2} b_{3} c_{2} d_{1}$ & $\ldots$ & $a_{3} b_{3} c_{1} d_{1}$ & $\mathrm{a}_{2} \mathrm{~b}_{4} \mathrm{c}_{1} \mathrm{~d}_{1}$ & $\ldots$ & $a_{2} b_{2} c_{1} d_{3}$ & $\mathrm{a}_{3} \mathrm{~b}_{2} \mathrm{c}_{1} \mathrm{~d}_{2}$ \\
\hline 6 & 9 & $a_{3} b_{1} c_{2} d_{3}$ & $a_{3} b_{4} c_{1} d_{1}$ & $a_{3} b_{2} c_{1} d_{3}$ & $a_{2} b_{3} c_{1} d_{3}$ & $\ldots$ & $a_{2} b_{4} c_{1} d_{2}$ & $a_{1} b_{5} c_{1} d_{2}$ & $\ldots$ & $a_{1} b_{4} c_{1} d_{3}$ & $\mathrm{a}_{1} \mathrm{~b}_{4} \mathrm{c}_{2} \mathrm{~d}_{2}$ \\
\hline 7 & 10 & $a_{1} b_{4} c_{2} d_{3}$ & $a_{2} b_{3} c_{2} d_{3}$ & $a_{3} b_{2} c_{2} d_{3}$ & $a_{1} b_{5} c_{1} d_{3}$ & $\ldots$ & $a_{2} b_{5} c_{2} d_{1}$ & $a_{3} b_{4} c_{1} d_{2}$ & $\ldots$ & $a_{3} b_{3} c_{1} d_{3}$ & \\
\hline 8 & 11 & $a_{3} b_{5} c_{1} d_{2}$ & $a_{3} b_{5} c_{2} d_{1}$ & $a_{3} b_{4} c_{2} d_{2}$ & $\mathrm{a}_{2} \mathrm{~b}_{5} \mathrm{c}_{2} \mathrm{~d}_{2}$ & $\ldots$ & $a_{3} b_{4} c_{1} d_{3}$ & $a_{1} b_{5} c_{2} d_{3}$ & & & \\
\hline 9 & 12 & $a_{3} b_{5} c_{2} d_{2}$ & $a_{3} b_{5} c_{1} d_{3}$ & $a_{3} b_{4} c_{2} d_{3}$ & $a_{2} b_{5} c_{2} d_{3}$ & & & & & & \\
\hline 10 & 13 & $a_{3} b_{5} c_{2} d_{3}$ & & & & & & & & & \\
\hline
\end{tabular}

Table 3. Availability matrix.

\begin{tabular}{|c|c|c|c|c|c|c|c|c|c|c|c|}
\hline \multirow{2}{*}{ Group } & $\begin{array}{c}\text { Index } \\
\text { sum }\end{array}$ & \multicolumn{10}{|c|}{ Availability of combinations } \\
\hline 1 & 4 & $\bullet$ & & & & & & & & & \\
\hline 2 & 5 & $\bullet$ & $\times$ & $\bullet$ & $\circ$ & & & & & & \\
\hline 3 & 6 & $\circ$ & $\times$ & $\bullet$ & $\circ$ & $\ldots$ & $\bullet$ & $\times$ & & & \\
\hline 4 & 7 & $\bullet$ & $\bullet$ & $\times$ & $\times$ & $\ldots$ & $\bullet$ & $\times$ & $\ldots$ & $\times$ & \\
\hline 5 & 8 & $\times$ & $\circ$ & $\times$ & $\times$ & $\ldots$ & $\bullet$ & $\circ$ & $\ldots$ & $\times$ & $\circ$ \\
\hline 6 & 9 & $\times$ & $\circ$ & $\circ$ & $\times$ & $\ldots$ & $\circ$ & $\bullet$ & $\ldots$ & $\circ$ & $\circ$ \\
\hline 7 & 10 & $\circ$ & $\times$ & $\times$ & $\circ$ & $\ldots$ & $\times$ & $\circ$ & $\ldots$ & $\circ$ & \\
\hline 8 & 11 & $\bullet$ & $\times$ & $\circ$ & $\times$ & $\ldots$ & $\circ$ & $\times$ & & & \\
\hline 9 & 12 & $\times$ & $\times$ & $\circ$ & $\times$ & & & & & & \\
\hline 10 & 13 & $\times$ & & & & & & & & & \\
\hline
\end{tabular}


Following the analysis of the combinations given by the constructive combination matrix, three types of combinations were found and put into an availability matrix, shown in Table 3 :

- existing or known constructive combinations, marked with $\bullet$ symbol;

- incompatible constructive combinations (for example, pairs of $b_{2} c_{2}$ or $b_{3} c_{2}$ type), marked with $\times$ symbol;

- new or different constructive combinations (possible in the present or in the future), marked with $\circ$ symbol.

Considering all possible combinations presented in the constructive combination matrix, as an example, a proposal for the construction of a different faucet body obtained through this method will be made. Thus, the type of faucet body from which it starts (Figure 1) can be identified as the $a_{1} b_{2} c_{1} d_{1}$ combination. Through the lexicographic technique, a number of 90 possible constructive combinations were obtained. Therefore, eliminating all existing combinations, but also incompatible ones, there remains a number of new or different combinations to be tested.

To exemplify the applicability of this method, $a_{3} b_{2} c_{1} d_{3}$ combination of the viable ones is chosen. This combination is represented by a faucet that can be operated with a lever or butterfly $\left(a_{3}\right)$, as a blocking element it has a plug $\left(b_{2}\right)$, the passage space is as wide as possible $\left(c_{1}\right)$ and the position of the actuating rod is tilted to the axis of the faucet body $\left(\mathrm{d}_{3}\right)$. As a result of this combination and keeping the general characteristics of the geometry from which, it was started, the faucet body shown in Figure 2 was obtained. This way, the restriction area could be enlarged from $18 \mathrm{~mm}$ to $25 \mathrm{~mm}$.
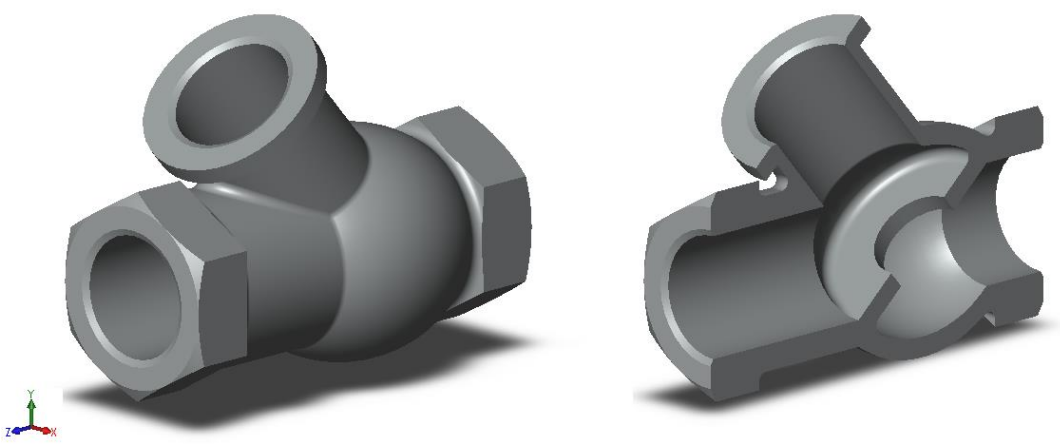

Fig. 2. Faucet body obtained as a result of the $\mathrm{a}_{3} \mathrm{~b}_{2} \mathrm{c}_{1} \mathrm{~d}_{3}$ combination.

\subsection{Flow simulation and comparison between constructive combinations}

By analyzing the flow simulation through the SolidWorks 2019 platform, important data can be obtained on the variation of pressure, vorticity and velocity in the faucet body.

In order to be able to observe the possible differences between the two faucet bodies, it was established that the working fluid pressure should be 5 bar, a pressure that represents the maximum level that could exist in a common installation. Since the analysis is focused on the general geometry of the faucet body, in performing the flow analysis, it was decided, in both cases, to plug the bore into which the bonnet is screwed. Obviously, both faucet bodies have the same 1-1/4-12 thread at both ports.

Given that the present simulation is an optimization step in the process of obtaining a product, several initial parameters have been introduced. Therefore, an internal flow simulation was performed where a gravitational component was introduced, the liquid flow was assumed as linear and turbulent, the walls of the faucet body have an adiabatic characteristic, the roughness of the walls is $0.4 \mu \mathrm{m}$ and $500000 \mathrm{~Pa}$ or $5 \mathrm{bar}$ is the inlet pressure.

Finally, the comparison between the two components is made between the results regarding the variation of the pressure in the faucet body, but especially in the restriction area. Also, the variation of the fluid velocity is also an aspect analyzed following the flow simulation. Last but not least, the intensity of the vorticity that varies especially after the restriction area is also important.

\section{RESULTS AND DISCUSSION}

In the case of $a_{1} b_{2} c_{1} d_{1}$ combination, due to drag in the faucet body walls and position of the baffle wall, the inlet pressure of 5.0 bar becomes 4.977 bar. There is a drop in pressure of about $46.5 \%$ just before the bore that connects to the outlet of the faucet body (Figure 3). There is a drop in pressure of about $44.2 \%$ just before the restriction 
area to the outlet of the faucet body (Figure 4). Closely related to the pressure variation, the maximum fluid velocity of $27.55 \mathrm{~m} / \mathrm{s}$ is achieved immediately after the fluid passes into the outlet area and forms vortices with much higher intensity (Figure 5).

Regarding the $\mathrm{a}_{3} \mathrm{~b}_{2} \mathrm{c}_{1} \mathrm{~d}_{3}$ combination, due to drag in the faucet body walls and the new position of the baffle wall, the inlet pressure of 5.0 bar becomes 4.75 bar. The pressure variation ensures a fluid velocity of $27.1 \mathrm{~m} / \mathrm{s}$ which is slightly lower than in the previous case. The fluid velocity increases just immediately after the fluid passes through the restriction of the outlet area and forms vortices with a considerably lower intensity compared with the previous case (Figure 6). The geometry of the baffle and the position of the bore cause the appearance of vortices of about $8553.85 \mathrm{~s}^{-1}$, that swirls the working fluid which could have a negative effect on it (Figure 7).

The planar geometry of the baffle causes the appearance of vortices of about $5315.5 \mathrm{~s}^{-1}$, which is a $37.86 \%$ decrease compared to the initial combination (Figure 8).

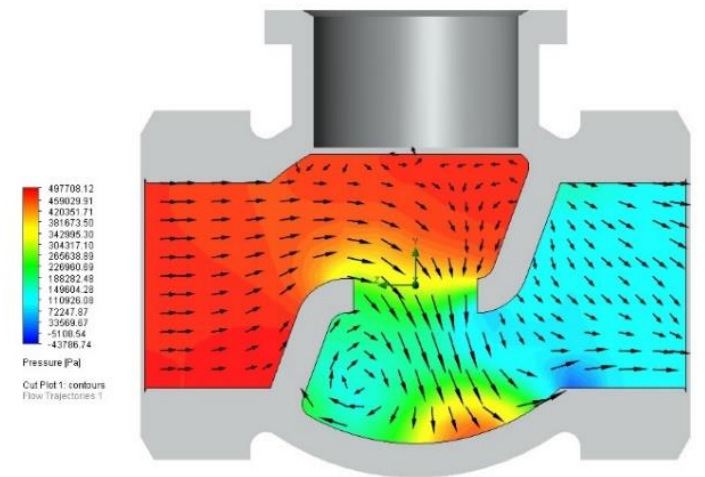

Fig. 3. Pressure variation obtained by means of flow simulation of $a_{1} b_{2} c_{1} d_{1}$ model.

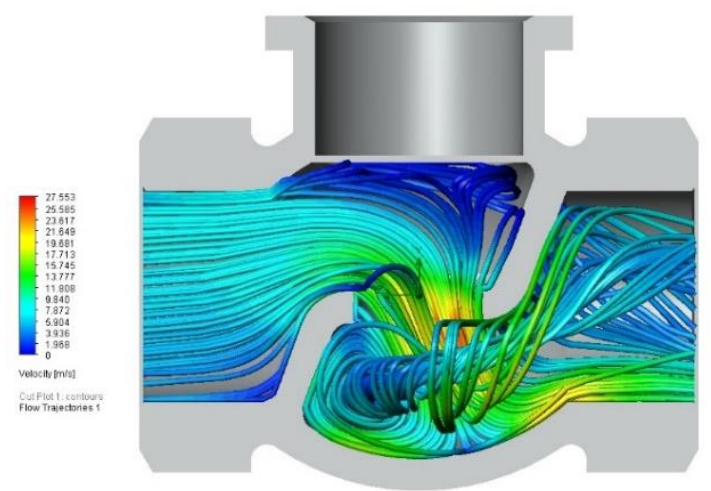

Fig. 5. Velocity variation obtained by means of flow simulation $\mathrm{a}_{1} \mathrm{~b}_{2} \mathrm{c}_{1} \mathrm{~d}_{1}$ model.

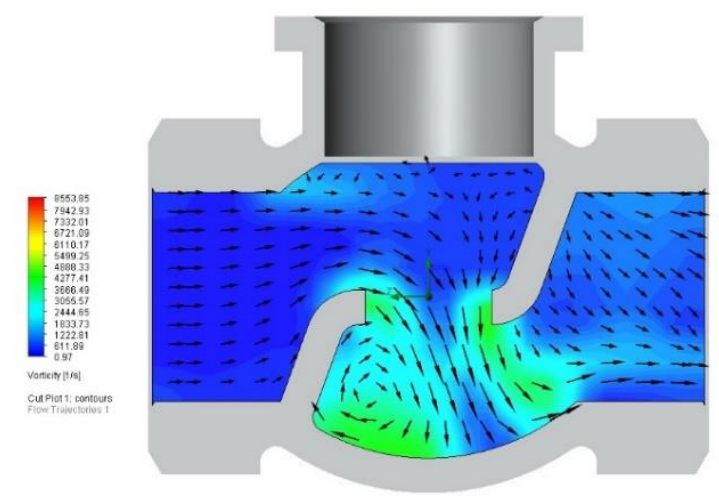

Fig. 7. Vorticity variation obtained by means of flow simulation $\mathrm{a}_{1} \mathrm{~b}_{2} \mathrm{c}_{1} \mathrm{~d}_{1}$ model.

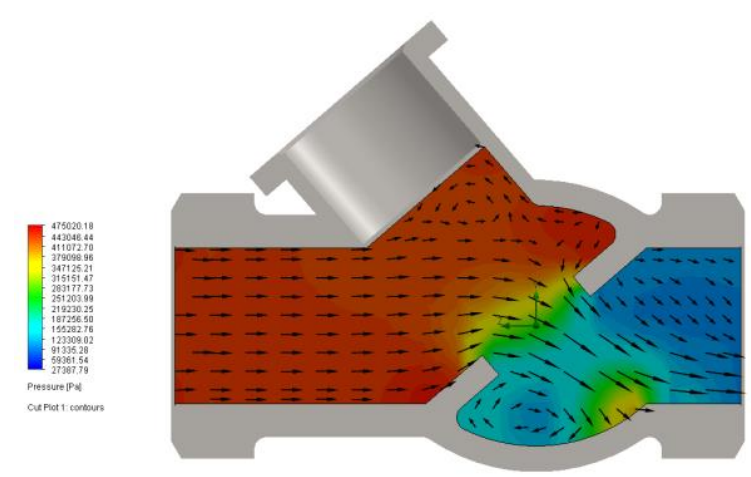

Fig. 4. Pressure variation obtained through flow simulation of $a_{3} b_{2} c_{1} d_{3}$ model.

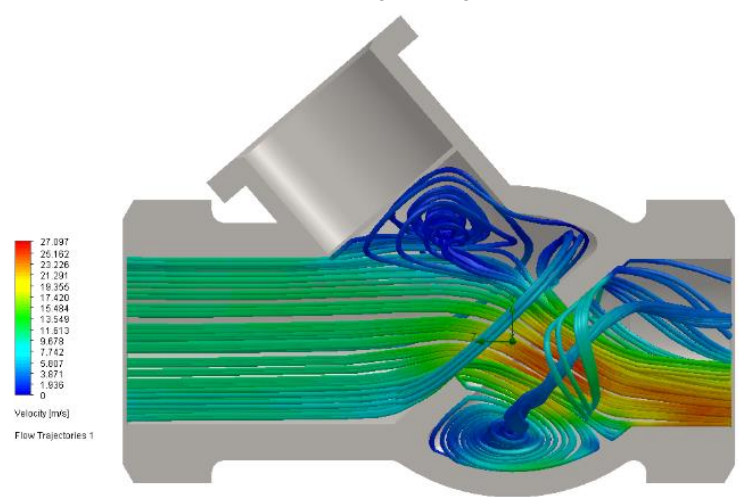

Fig. 6. Velocity variation obtained through flow simulation of $a_{3} b_{2} c_{1} d_{3}$ model.

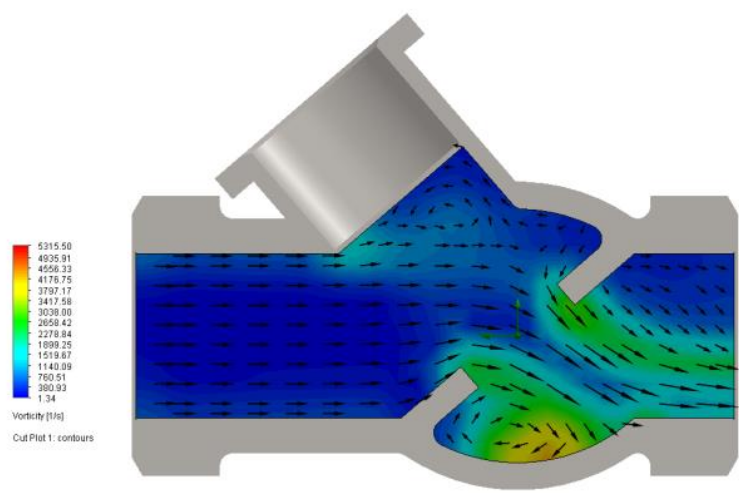

Fig. 8. Vorticity variation obtained through flow simulation of $\mathrm{a}_{3} \mathrm{~b}_{2} \mathrm{c}_{1} \mathrm{~d}_{3}$ model. 


\section{CONCLUSIONS}

Following the application of the lexicographic technique to obtain a different product, the following conclusions can be drawn:

- although a reasonable number of combinations can be obtained, the method is quite time consuming in order to check all possible solutions;

- the method is quite simple to apply, the results obtained being limited only by current technological possibilities; - the method is safe regarding orderly enumeration of all assemblies, without omissions or repetitions.

Following the undergoing of flow simulations for both faucet bodies, the following can be emphasized: - the tilted positioning of the baffle has a positive effect in terms of the appearance and intensity of vortices; in the case of $a_{3} b_{2} c_{1} d_{3}$ combination, the intensity of the vortices decreases by $37.86 \%$ compared to the version from which this study was started;

- also, due to the new position of the baffle, the dimensions of the seat could be increased, allowing a larger volume of fluid to pass through;

- as the intensity of the vortices decreases, the fluid flows much more linearly, without major turbulence.

Analyzing all the above, it can be strongly concluded that by using analytical methods specific to creativity, such as the lexicographic method, not only can it successfully obtain new or different products, but it can also fine-tune these products.

\section{REFERENCES}

[1] Bellenger, L., Sève, M.M., Boost your creativity (in French), Ed. ESF, 2007.

[2] Steinerova, J., Perceptions of the information environment by researchers: a qualitative study, Proceedings of ISIC: The Information Behavior Conference, Poland, vol. 23, no. 4, 2018, http://informationr.net/ir/234/isic2018/isic1812.html (26.07.2020).

[3] Savoyat, B., Les secrets de l'efficacité - un fair plus ... en moins de temps. Ed. Maxima, Paris, 2006.

[4] Paicu, G., Creativity - fundamentals, secrets and strategies, $2^{\text {nd }}$ edition (in Romanian), Ed. PIM, Iasi, 2011.

[5] Theriault, M., Great maritime inventions, 1833-1950 (eBOOK), Ed. Goose Lane, 2011. 